Reprod. Nutr. Dévelop., 1988, 28 Suppl. n¹, 133-134

\title{
Etude de la disparition des acides aminés alimentaires dans le rumen et dans l'intestin à l'aide de la méthode des sachets nylon
}

\author{
L. LE HENAFF, H. RULQUIN, J. L. PEYRAUD
}

Station de Recherches sur la Vache Laitière,

I.N.R.A., Saint-Gilles, 35590 L'Hermitage, France.

Summary. The amino acid (AA) composition of rumen "by-pass » and undigestible proteins differ from that of original feedstuffs. For all the feedstuffs, lysine, isoleucine, phenylalanine are greater and histidine lower in the «by-pass » fraction; Iysine and valine are greater and leucine lower in the undigestible protein.

Chez les ruminants, les effets des processus digestifs sur la composition en acides aminés (AA) des fractions non dégradables dans le rumen et indigestibles dans l'intestin sont mal connus. Pour simuler ces effets, nous avons déterminé, sur cinq aliments, la composition en AA des protéines résiduelles en sachets de nylon, après un séjour dans le rumen ou après passage dans l'intestin.

Matériel et méthodes. Les aliments étudiés sont un tourteau de soja, un ensilage de maïs, un foin de ray grass anglais, un concentré riche en parois cellulaires et un concentré riche en amidon (tabl. 1). Les mesures ont été effectuées sur deux vaches munies de canules de rumen et du duodénum proximal recevant une ration standard (Michalet-Doreau et al., 1987). La fraction non dégradable dans le rumen a été obtenue après incubation dans des sachets nylon (dimensions $7,5 \times 15 \mathrm{~cm}$, pores de $46 \mu \mathrm{m}, 3 \mathrm{~g}$ de MS) pendant $15 \mathrm{~h}$ dans le rumen (Michalet-Doreau et al., 1987). La fraction indigestible a été obtenue après une incubation de $15 \mathrm{~h}$ dans le rumen en mini-sachets (dimensions $6 \times 6 \mathrm{~cm}$, pores de $46 \mu \mathrm{m}, 1,5 \mathrm{~g}$ de $\mathrm{MS}$ ), attaque pepsique et transit dans l'intestin à partir de la canule duodénale (Peyraud et al., 1988). Après congélation $\left(-18{ }^{\circ} \mathrm{C}\right)$, tous les sachets ont été rincés énergiquement pendant $45 \mathrm{~min}$ en machine à laver à tambour horizontal avant séchage. Les AA et l'acide diaminopimélique (DAPA) ont été dosés dans les aliments et les deux résidus, par chromatographie après hydrolyse par $\mathrm{HCl} 6 \mathrm{~N}$ pendant 18,24 et $48 \mathrm{~h}$, les $\mathrm{AA}$ soufrés ayant subi une oxydation performique préalable.

Résultats et discussion. La colonisation bactérienne des matières azotées résiduelles à la sortie du rumen et de l'intestin, estimée par le DAPA, ne semble pas importante (moins de $2 \%$ ), en raison peut-être des traitements énergiques (congélation, rinçage) utilisés. Par rapport aux matières azotées d'origine, le pourcentage d'AA indispensables augmente dans les protéines des deux types de résidus, et ce pour chacun des aliments (tabl. 1). Dans les protéines résiduelles du rumen, les teneurs en histidine diminuent et celles en lysine, isoleucine et phénylalanine augmentent systématiquement, conformément aux résultats de 
TABL. 1. - Composition des acides aminés des protéines des aliments et des fractions non dégradées dans le rumen et dans le rumen plus l'intestin (g/100 g AA).

\begin{tabular}{|c|c|c|c|c|c|c|c|c|c|c|c|}
\hline & & PHE & MET & THR & LYS & HIS & ILE & LEU & VAL & ARG & AANI \\
\hline liments & $\begin{array}{l}\text { Tourteau de soja } \\
\text { Ensilage de maiss } \\
\text { Concentré parois } \\
\text { Concentré amidon } \\
\text { Foin de ray grass }\end{array}$ & $\begin{array}{l}5,8 \\
5,4 \\
5,2 \\
5,3 \\
5,7\end{array}$ & $\begin{array}{l}1,3 \\
1,8 \\
1,7 \\
1.8 \\
1,7\end{array}$ & $\begin{array}{l}4,1 \\
4,5 \\
4,1 \\
7,0 \\
4,9\end{array}$ & $\begin{array}{l}5,5 \\
4,2 \\
4,3 \\
2,9 \\
5,0\end{array}$ & $\begin{array}{l}2,9 \\
3,1 \\
3,4 \\
2,8 \\
2,1\end{array}$ & $\begin{array}{l}5,0 \\
4,4 \\
4,3 \\
4,2 \\
5,0\end{array}$ & $\begin{array}{r}8,9 \\
14,2 \\
8,7 \\
10,0 \\
9,4\end{array}$ & $\begin{array}{l}4,9 \\
6,2 \\
6,6\end{array}$ & $\begin{array}{l}6,4 \\
2,0 \\
7,8 \\
2,6 \\
3,9\end{array}$ & $\begin{array}{l}55,2 \\
54,1 \\
53,9 \\
57,5 \\
55,2\end{array}$ \\
\hline $\begin{array}{l}\text { Résidus } \\
\text { rumen }\end{array}$ & $\begin{array}{l}\text { Tourteau de soja } \\
\text { Ensilage de maïs } \\
\text { Concentré parois } \\
\text { Concentré amidon } \\
\text { Foin de ray grass }\end{array}$ & $\begin{array}{l}6,2 \\
6,8 \\
6,3 \\
6,5 \\
7,2\end{array}$ & $\begin{array}{l}1,4 \\
2,0 \\
2,2 \\
1,4 \\
2,3\end{array}$ & $\begin{array}{l}4,0 \\
5,4 \\
5,4 \\
4,2 \\
5,4\end{array}$ & $\begin{array}{l}6,0 \\
5,7 \\
4,5 \\
2,8 \\
5,4\end{array}$ & $\begin{array}{l}2,6 \\
2,3 \\
2,6 \\
2,6 \\
1,8\end{array}$ & $\begin{array}{l}5,2 \\
5,1 \\
5,4 \\
4,6 \\
5,8\end{array}$ & $\begin{array}{r}9,3 \\
9,6 \\
10,0 \\
14,8 \\
10,3\end{array}$ & $\begin{array}{l}5,3 \\
5,9 \\
6,9 \\
5,3 \\
6,6\end{array}$ & $\begin{array}{l}7,3 \\
4,7 \\
3,9 \\
3,0 \\
5,9\end{array}$ & $\begin{array}{l}52,7 \\
52,5 \\
52,8 \\
54,8 \\
49,4\end{array}$ \\
\hline $\begin{array}{l}\text { Résidus } \\
\text { rumen }+ \\
\text { intestin }\end{array}$ & $\begin{array}{l}\text { Tourteau de soja } \\
\text { Ensilage de mais } \\
\text { Concentré parois } \\
\text { Concentré amidon } \\
\text { Foin de ray grass }\end{array}$ & $\begin{array}{l}3,9 \\
7,5 \\
5,7 \\
6,5 \\
5,1\end{array}$ & $\begin{array}{l}1,5 \\
1,2 \\
1,2 \\
1,6 \\
1,6\end{array}$ & $\begin{array}{l}3,2 \\
5,9 \\
5,3 \\
5,7 \\
7,4\end{array}$ & $\begin{array}{r}10,3 \\
6,9 \\
5,7 \\
5,7 \\
6,2\end{array}$ & $\begin{array}{l}4,4 \\
2,2 \\
2,5 \\
2,4 \\
3,1\end{array}$ & $\begin{array}{l}2,7 \\
4,0 \\
4,9 \\
4,5 \\
4,3\end{array}$ & $\begin{array}{l}4,7 \\
8,4 \\
9,0 \\
8,9 \\
7,4\end{array}$ & $\begin{array}{r}5,9 \\
6,8 \\
8,2 \\
7,7 \\
10,5\end{array}$ & $\begin{array}{l}3,2 \\
5,3 \\
4,9 \\
4,9 \\
6,2\end{array}$ & $\begin{array}{l}60,2 \\
51,8 \\
52,5 \\
52,0 \\
48,0\end{array}$ \\
\hline
\end{tabular}

AANI: Acides aminés non indispensables. Concentré parois: $33 \%$ de pulpes de betteraves déshydratées, $28 \%$ d'orge, $28 \%$ de son fin de blé, $11 \%$ de luzerne. Concentré amidon : $35 \%$ de mais grain, $27 \%$ de blé, $22 \%$ d'orge, $11 \%$ de son fin de blé et $5 \%$ de luzerne déshydratée.

Crooker et al. (1987). Le taux moyen de disparition dans le rumen le plus fort est celui de la valine $(84 \%)$, le plus faible étant celui de la leucine $(79 \%)$. Les protéines résiduelles à la sortie de l'intestin sont systématiquement plus pauvres en leucine et isoleucine et plus riches en lysine et valine par rapport aux matières azotées d'origine alimentaires. Elles s'appauvrissent en leucine et isoleucine et s'enrichissent en lysine et valine par rapport aux protéines résiduelles du rumen. Le taux moyen de disparition dans l'ensemble rumen + intestin des AA pour l'ensemble des aliments varie de $93 \%$ pour la lysine à $96 \%$ pour la leucine. La comparaison des taux de disparition dans l'intestin, pouvant toutefois être faussée par l'utilisation de sachets de taille différente, indique que la méthionine et la leucine seraient plus disponibles que la lysine dans cette partie du tube digestif (taux de disparition moyen dans l'intestin : 79 et $78 \%$ vs $65 \%$ ). II serait nécessaire de confirmer ces différences de disponibilités intestinales par des études de digestibilité utilisant un seul type de sachets, notamment dans le cas de la lysine qui semble être limitante chez la vache laitière.

Crooker B. A., Clark J. H., Shanks R. D., Fahey G. C. Jr., 1987. Can. J. anim. Sci., 67, 1143-1147 Michalet-Doreau B., Vérité R., Chapoutot P., 1987. Bull. Tech. C.R.Z.V. Theix, I.N.R.A., (69), 5-7. Peyraud J. L., Genest-Rulquin C., Vérité R., 1988. Reprod. Nutr. Dévelop., 28, suppl. $n^{\circ} 1,129-130$. 